\title{
Interaction effects between estrogen receptor $\alpha$ gene, vitamin $D$ receptor gene, age, and sex on bone mineral density in Chinese
}

Received: 9 June 2003/ Accepted: 24 July 2003 / Published online: 19 September 2003

(C) The Japan Society of Human Genetics and Springer-Verlag 2003

\begin{abstract}
We evaluated the interaction effects between the estrogen receptor $\alpha$ gene $(E R-\alpha)$, vitamin $D$ receptor gene (VDR), age and sex on bone mineral density (BMD) in a sample of 340 unrelated males and 297 unrelated females from 401 Chinese nuclear families. Polymorphisms of $P v u \mathrm{II}$ and $X b a \mathrm{I}$ in the ER- $\alpha$ gene and ApaI in the VDR gene were detected by RFLP, and ER$\alpha$ genotype was defined by the haplotype reconstructed according to the two loci. In the females, significant ERVDR gene interaction $(P<0.05)$ was found on the lumbar spine BMD. Such interaction might account for approximately $1.0 \%$ of the BMD variation. At the femoral neck and trochanter, significant ER-age interaction effects were observed, which might explain $0.3 \%$ BMD variation for both skeletal sites. In the males, significant VDR-age interaction was found on femoral neck BMD $(P<0.05)$, and it accounted for $0.6 \%$ BMD variation. These interaction effects were largely dependent on gender groups, suggesting there may exist ERVDR-sex, ER-age-sex, and VDR-age-sex complex interactions in our Chinese sample.
\end{abstract}

Keywords Interaction ER- $\alpha$ gene $\cdot$ VDR gene Bone mineral density $($ BMD) $\cdot$ Age $\cdot$ Sex

\footnotetext{
J. Long · H.-W. Deng

Laboratory of Molecular and Statistical Genetics, College of Life Sciences, Hunan Normal University, 410081 Changsha, Hunan, P. R. China

J. Long · P. Liu · Y. Zhang $\cdot$ H. Shen $\cdot$ Y. Liu · V. Dvornyk H.-W. Deng $(\bowtie)$

Osteoporosis Research Center,

Creighton University Medical Center,

601 N. 30th St., Suite 6787, Omaha, NE 68131, USA

E-mail: deng@creighton.edu

Tel.: + 1-402-280-5911

Fax: + 1-402-280-5034
}

\section{Introduction}

Osteoporosis is among the major health problems throughout the world. It is characterized by low bone mineral density (BMD) and microarchitectural deterioration of bone structure (Kanis et al. 1994). BMD variation is under strong genetic determination with heritability of over $50 \%$ (Recker and Deng 2002). A number of candidate genes associated with BMD have been identified, such as estrogen receptor $\alpha$ (ER- $\alpha$ ), vitamin D receptor (VDR), calcitonin receptor, collagen type $1 \alpha 1$ (COL1A1), interleukin-6, transforming growth factor $\beta 1$, and others (Ralston 2002; Liu et al. 2003). Among them, polymorphisms of $P v u \mathrm{II}$ and $X b a \mathrm{I}$ sites in the ER- $\alpha$ gene (ER-PvuII and ER-XbaI), and $A p a \mathrm{I}$ site in the VDR gene (VDR-ApaI) have been the most extensively studied genetic markers in relation to BMD variation (Ralston 2002; Liu et al. 2003). However, the results so far have been largely inconsistent and controversial.

To some extent, the association between a candidate gene and BMD may depend on other factors, such as environment, gene-gene and gene-nongenetic factor interactions (Ralston 2002; Liu et al. 2003). Gene-gene interaction implies that genotypic effects of one locus may depend on the genotype of the other locus (or loci), while gene-nongenetic factor interaction means that only under particular conditions, such as specific age or sex, will the genotypes affect phenotypes. If such interaction effects exist and are not taken into account, they could confound, and even bias, the associations between the candidate genes and the phenotypes (Deng et al. 1998). Gene-gene interactions between the VDR, ER- $\alpha$, and COLIA1 genes, as well as the interactions between genes and nongenetic factors, e.g., sex, age, race, calcium intake, vitamin D supplements, hormone replacement therapy (HRT), and exercise, were recently documented (Graafmans et al. 1997; Giguere et al. 2000; Efstathiadou et al. 2001; Dennison et al. 2001; Rapuri et al. 2001; Salmen et al. 2001; Tofteng et al. 2002). However, most 
of these studies were performed in Caucasians, and scarce data are available about the interaction effects on BMD in Chinese (but see Zhao et al. 1997; Lau et al. 2001, 2002).

The present study was aimed to determine if there are interaction effects between the ER- $\alpha$ and VDR genes, as well as between these genes and age, on BMD variation in healthy Chinese males and females.

\section{Materials and methods}

Subjects

The subjects were selected from 401 nuclear families (each with both parents and at least one female child) used in our early study (Qin et al. 2003), which was approved by the Research Administration Department of Shanghai's Sixth People's Hospital and Hunan Normal University. All subjects signed informed-consent documents. The following data from the subjects were obtained: age, sex, medical history, and family history. Exclusion criteria were used to minimize any known potential confounding factors on the study phenotypes as detailed by Deng et al. (2002a). In brief, subjects with the following diseases were excluded: diabetes mellitus, cancer, exostosis, hepatopathy, high blood pressure, hyperthyroidism, kidney disease, parathyroid disease, rheumatoid arthritis, ovary resection, and tuberculosis. To get unrelated individual samples, only phenotypes from parents of each nuclear family were used in this study. Excluding those under 50 years old (because of the small sample size), and pre/perimenopausal women (to keep the subjects homogeneous), the phenotypes of 340 males and 297 postmenopausal females were analyzed.

\section{Genotyping}

Genotypes of all subjects in the 401 nuclear families were determined using PCR-RFLP reaction protocols as described by Lei et al. (2003). The genotypes were designated as $P P, P p, p p$ for ER$P v u \mathrm{II}, X X, X x, x x$ for ER- $X b a \mathrm{I}$, and $A A, A a, a a$ for VDR- $A p a \mathrm{I}$. Uppercase and lowercase letters denote the absence and presence of the restriction sites, respectively. PedCheck software (O'Connell and Week 1998) was used to verify Mendelian inheritance of the alleles within each family.

\section{Measurement}

A Hologic QDR 2000 + dual-energy X-ray absorptiometry (DXA) scanner (Hologic Corporation, Waltham, MA, USA) was used to measure BMD of lumbar spine (L1-L4) and total hip (including femoral neck, trochanter and intertrochanteric regions), and reports BMD in grams per centimeter squared. The machine was calibrated daily. The coefficient of variability (CV) of the accuracy of DXA measurement at the spine, total hip, femoral neck, trochanter, and intertrochanteric region was $0.9 \%, 0.8 \%, 1.93 \%$, $1.48 \%$, and $1.31 \%$, respectively. Weight and height were measured at the same time of BMD measurement.

Statistical analyses

The $\chi^{2}$ test was performed to examine Hardy-Weinberg equilibrium (HWE) at the three marker loci. ER- $\alpha$ haplotypes were reconstructed according to all subjects from the nuclear families using the program SimWalk2 (Sobel and Lange 1996). Multiple linear regression analyses were performed to examine the interaction effects on BMD variation in males and females. The regression variables were age, height, weight, ER- $\alpha$ (defined by the haplotype), VDR, ER-age interaction, VDR-age interaction, and ER-VDR interaction. The frequency of genotype $A A$ for VDR gene was low: $7.35 \%$ in males and $7.74 \%$ in females. If the subjects were divided to three groups, $a a, A a$, and $A A$, the sample sizes for some groups were small, and it was not appropriate to analyze the interaction effects. Then genotypes $A a$ and $A A$ were combined into one group and coded as " 1 ", another group, $a a$, was coded as " 2 ". To analyze the effect of a special ER- $\alpha$ haplotype, the subjects with this haplotype were denoted as " 1 "; those without it were denoted as " 2 ", In males, there were $97,276,118$, and 49 subjects denoted as " 1 " for the haplotypes $P X, p x, P x$, and $p X$, respectively, while in females, there were $95,220,116$, and 50 individuals denoted as " 1 ", respectively. The interaction terms of ER-age, VDR-age, and ERVDR were the products of ER- $\alpha$ and age, VDR and age, VDR and ER- $\alpha$. These statistical analyses were performed using SAS version 8.0 (SAS Institute, Cary, NC, USA).

\section{Results}

Descriptive characteristics of the subjects are summarized in Table 1. The male subjects in the study were
Table 1 Descriptive characteristics of the study subjects

Values shown are mean \pm standard deviation; values are raw data

$* \chi^{2}$-test for Hardy-Weinberg equilibrium, $P<0.05$ at ER$X b a \mathrm{I}$ both in the males and the females, $P>0.1$ at ER- $P v u \mathrm{II}$ and VDR-ApaI both in the males and the females

\begin{tabular}{lcc}
\hline Trait & Male $(n=340)$ & Female $(n=297)$ \\
\hline Age (year) & $62.91 \pm 6.11$ & $60.27 \pm 5.78$ \\
Height $(\mathrm{cm})$ & $165.57 \pm 10.80$ & $154.36 \pm 5.49$ \\
Weight $(\mathrm{kg})$ & $68.18 \pm 10.33$ & $59.21 \pm 8.44$ \\
Lumbar spine $(\mathrm{L} 1-\mathrm{L} 4) \mathrm{BMD}\left(\mathrm{g} / \mathrm{cm}^{2}\right)$ & $0.931 \pm 0.153$ & $0.799 \pm 0.145$ \\
Total hip BMD $\left(\mathrm{g} / \mathrm{cm}^{2}\right)$ & $0.876 \pm 0.124$ & $0.737 \pm 0.129$ \\
Femoral neck BMD $\left(\mathrm{g} / \mathrm{cm}^{2}\right)$ & $0.751 \pm 0.116$ & $0.664 \pm 0.116$ \\
Trochanter BMD $\left(\mathrm{g} / \mathrm{cm}^{2}\right)$ & $0.649 \pm 0.101$ & $0.535 \pm 0.102$ \\
Intertrochanteric region BMD $\left(\mathrm{g} / \mathrm{cm}^{2}\right)$ & $1.025 \pm 0.149$ & $0.869 \pm 0.156$ \\
ER- $\alpha$ gene allele/haplotype frequencies $(\%)$ & & \\
$P$ & 34.26 & 40.07 \\
$p$ & 65.74 & 59.93 \\
$X$ & $22.21 *$ & $26.26^{*}$ \\
$x$ & 77.79 & 73.74 \\
$P X$ & 15.15 & 18.01 \\
$p x$ & 58.68 & 51.68 \\
$P x$ & 18.97 & 8.42 \\
$p X$ & 7.20 & 27.69 \\
VDR gene allele frequencies $(\%)$ & 30.15 & 72.39 \\
$A$ & 69.85 & \\
$a$ & &
\end{tabular}


aged $62.91 \pm 6.11$ (mean \pm SD) years and ranged from 50.25 to 78.83 years. The female subjects were averaged $60.27 \pm 5.78$ years, with the range from 50.00 to 76.67 years. The frequencies of the alleles and/or haplotypes are also summarized in Table 1 . The $\chi^{2}$ tests showed that the ER-PvuII and VDR-ApaI polymorphisms were in HWE $(P>0.1)$ both in males and females, whereas ER$X b a \mathrm{I}$ was not $(P<0.05)$.

The results of multiple linear regression analyses in the females are shown in Table 2 . We observed a significant ER-VDR interaction effect on lumbar spine BMD $(P<0.05)$. Only when the VDR genotype was $a a$ was the difference statistically significant for the lumbar spine BMD between the subjects with haplotype $p X$ and without it, $\left(0.840 \pm 0.143\right.$ versus $0.779 \pm 0.139 \mathrm{~g} / \mathrm{cm}^{2}$, $P<0.05)$. Significant gene-age interaction effects were found for ER- $\alpha p X$ haplotype on both femoral neck BMD $(P<0.05)$ and trochanter BMD $(P<0.05)$. No such effect was observed either for any other ER- $\alpha$ haplotypes (data not shown) or the VDR gene at any skeletal site studied (Table 2).

The results of regression analyses in the males were quite different from those in the females (Table 3). The only significant interaction effect in the males was observed between VDR and age on femoral neck BMD $(P<0.05)$. No evidence was obtained for the ER-age and ER-VDR effects on the BMD variations at any skeletal site (data not shown).

As expected, when the interaction terms were removed from the multiple regression model, the percentage of variation explained by the model, as reflected by the adjusted $\mathrm{R}^{2}$, was decreased (Table 2 ). The differences in the $R^{2}$ values of the multiple regression analyses with and without the interaction terms approximately equaled to the percentage of BMD variation, which may be attributed to the significant interaction effects. In the females, about $1.0 \%$ spine BMD variation may be due to the ER-VDR interaction, while the ER-age interaction can account for about $0.3 \%$ femoral neck BMD and $0.3 \%$ trochanter BMD variation (Table 2). In the males, $0.6 \%$ BMD variation at the femoral neck was due to the VDR-age interaction. Another finding of this study is, in the females, when the interaction factors were incorporated in the regression model, BMD variations were significantly affected by ER- $\alpha$ genotypes at the femoral neck and trochanter (Table 2). When the interaction factors were removed from the regression model, the ER- $\alpha$ effect appeared to be nonsignificant.

\section{Discussion}

In the recent past, extensive molecular genetic studies have been launched to identify genes underlying BMD variations (Liu et al. 2003). However, only a few studies analyzed the interaction effects of gene-gene and genenongenetic factors. Such interactions may vary in different populations (Dennison et al. 2001) and may influence the association between the candidate genes and BMD variation. For example, Willing et al. (1998) found that ER-PvuII and ER-XbaI interacted with VDR-BsmI to have an effect on BMD variations at the femoral neck, lumbar spine, and total body in Caucasian females. In Italian postmenopausal women, subjects with genotype $A A B B t t-P P X X$ had significant lower spine BMD than those with aabbTT-ppxx genotype (Gennari et al. 1998). In Korean women, effects of ER- $\alpha$ genotype on BMD at the Ward's triangle were observed only when combined with the VDR FokI genotype FF (Kim et al. 2001). Such VDR-ER interaction effects, between VDR-ApaI with ER-PvuII and ER-XbaI were also observed on BMD changes in both the placebo and HRT groups in postmenopausal Caucasian women (Deng et al. 1998). The results of all these studies are in general agreement with the findings of the present study. The mechanism of ER-VDR interaction on BMD variation is still unclear; however, it is consistent with the

Table 2 Results of multiple regression analyses in the females

\begin{tabular}{|c|c|c|c|c|c|c|c|c|c|c|}
\hline Trait (BMD) & Intercept & $\mathrm{ER}-\alpha^{\dagger}$ & VDR & Age & Height & Weight & ER-age & VDR-age & ER-VDR & Adj. $\mathrm{R}^{2 \S}$ \\
\hline \multicolumn{11}{|l|}{ With interaction factors } \\
\hline Lumbar spine & 0.414 & 0.192 & -0.171 & $-0.005^{* *}$ & -0.001 & $0.008 * *$ & -0.004 & 0.003 & $0.085^{*}$ & 0.288 \\
\hline Femoral neck & $0.508 * *$ & $-0.299 *$ & 0.046 & $-0.006^{* *}$ & -0.001 & $0.006 * *$ & $0.005^{*}$ & -0.001 & 0.001 & 0.365 \\
\hline Trochanter & $0.469 *$ & $-0.268 *$ & 0.062 & $-0.005 * *$ & -0.001 & $0.006^{* *}$ & $0.004^{*}$ & -0.001 & 0.017 & 0.352 \\
\hline Intertrochanteric region & $0.742 * *$ & -0.163 & 0.093 & $-0.008 * *$ & 0.001 & $0.009 * *$ & 0.003 & -0.002 & 0.023 & 0.366 \\
\hline \multicolumn{11}{|c|}{ Without interaction factors } \\
\hline Femoral neck & 0.532 & 0.012 & -0.013 & $-0.006^{* *}$ & -0.001 & $0.006 * *$ & & & & 0.362 \\
\hline Trochanter & $0.505 * *$ & -0.008 & -0.012 & $-0.005^{* *}$ & -0.001 & $0.006 * *$ & & & & 0.349 \\
\hline Intertrochanteric region & $0.802 * *$ & 0.024 & -0.009 & $-0.008 * *$ & 0.001 & $0.009 * *$ & & & & 0.365 \\
\hline
\end{tabular}

\footnotetext{
$\dagger$ The results are given only for haplotype $p X$. The other haplotypes yielded no significant results (data not shown)

$\S \mathrm{Adj} . \mathrm{R}^{2}$ is the proportion of variation of the dependent variable explained by the regression model. Other numbers in the table are the partial regression coefficients for the parameters of each factor

$* P<0.05$

$* * P<0.01$
} 
Table 3 Results of multiple regression analyses in the males

\begin{tabular}{lcrlrrrrrrrr}
\hline $\begin{array}{l}\text { Trait (BMD) } \\
\text { With interaction factors }\end{array}$ & Intercept & ER- $\alpha^{\dagger}$ & VDR & Age & Height & Weight & ER-age & VDR-age & ER-VDR & Adj.R ${ }^{2 \S}$ \\
\hline Lumbar spine & $0.667^{* *}$ & 0.282 & -0.012 & 0.001 & -0.001 & $0.006^{* *}$ & -0.005 & 0.001 & -0.004 & 0.139 \\
Total hip & $1.132^{* *}$ & 0.047 & -0.140 & $-0.005^{* *}$ & $-0.002^{* *}$ & $0.007^{* *}$ & -0.001 & 0.002 & 0.011 & 0.295 \\
Femoral neck & $0.951^{* *}$ & 0.094 & -0.216 & $0.005^{* *}$ & $-0.002^{* *}$ & $0.006^{* *}$ & -0.002 & $0.003^{*}$ & 0.011 & 0.253 \\
Trochanter & $0.806^{* *}$ & 0.043 & -0.127 & $-0.003^{* *}$ & $-0.002^{* *}$ & $0.005^{* *}$ & -0.001 & 0.002 & 0.011 & 0.217 \\
Intertrochanteric region & $1.349^{* *}$ & -0.045 & -0.147 & $-0.006^{* *}$ & $-0.003^{* *}$ & 0.008 & 0.001 & 0.002 & 0.012 & 0.282 \\
\hline
\end{tabular}

\footnotetext{
$\dagger$ The results are given only for haplotype $p X$. The other haplotypes yielded no significant results (data not shown)

$\S \operatorname{Adj} . \mathrm{R}^{2}$ is the proportion of variation of the dependent variable explained by the regression model. Other numbers in the table are the partial regression coefficients for the parameters of each factor

$* P<0.05$

$* * P<0.01$
}

evidence that estrogens modulate the activity of 1,25 dihydroxyvitamin $\mathrm{D}$ receptors in osteoblast-like cells (Liel et al. 1992). In addition, vitamin D and its reception may influence the balance between androgens and estrogens in peripheral tissues, which in turn modulates the availability of steroid hormones for their receptors (Willing et al. 1998).

On the other hand, no VDR-ER interaction effects were found in Greek postmenopausal women (Efstathiadou et al. 2001) and an elderly white women population (Brown et al. 2001). The inconsistent results of the different studies may be due to interstudy differences in ethnicity, sample size, age, population structure and employed statistical methods. For example, if the sample size is insufficiently large, the power to detect the interaction effects will be very low, especially for genetic markers with low allele frequencies. On the other hand, the effects of the main genotypes and/or gene-gene interaction may be masked and not detected in a case, when actually existing significant nongenetic effects or gene-nongenetic interaction effects are not incorporated into the analyses. Population admixture/stratification may lead to deviation of genotype frequencies from HWE (Schaid and Jacobsen 1999). Such deviations from HWE have been observed in some studies of the ER- $\alpha$ polymorphisms (e.g., Ho et al. 2000; Kim et al. 2001) and in the present study as well. Our samples were recruited from a local population of Shanghai City, a metropolitan area and home to tens of millions of people from different geographical areas. It is possible that there exists heterogeneity at ER-XbaI locus but not at the other two loci examined in the present study.

In addition to gene-gene interactions, gene-nongenetic factor interactions may also affect BMD variation. In the present study, we found significant ER-age effects on trochanter BMD and femoral neck BMD in the females, and VDR-age interaction on femoral neck BMD in the males. These gene-age interactions suggest that the dynamics of BMD change with aging may not be the same in groups with different ER- $\alpha$ genotype (with or without haplotype $p X$ ), or VDR genotype ( $a a$ or other two genotypes). Similar ER-age interaction effects on BMD variation have also been reported in other studies. Chinese women of 70-79 years old with the XX genotype had $80 \%$ of a standard deviation (SD) higher spine
BMD than those of other genotypes, while such difference was only $40 \%$ of an SD in younger women aged 55-59 years (Lau et al. 2001). In Japanese women, the effects of ER- $\alpha$ genotypes on BMD variation were observed in those aged 60 or over but not in those under 60 years (Yamada et al. 2002). VDR-age interactions were also observed in other studies. The VDR-FokI polymorphism was associated with BMD only in elderly Chinese women (70-79 years), but not in elderly men or younger women aged 50-59 years (Lau et al. 2002). VDR-ApaI and VDR-BsmI were associated with BMD only in the young Chinese women but not in the postmenopausal women (Zhao et al. 1997). In Caucasians, two studies indicated that the correlation of the VDR gene polymorphism with BMD tended to disappear with age and might exist only in the premenopausal (Riggs et al. 1995) or even the prepubertal period (Ferrari et al. 1998).

It is worth mentioning that in this study, the geneage, gene-gene interaction effects were different in the males and the females as outlined before, which implied that such interactions were influenced by sex, i.e., there may exist complex interactions such as VDR-age-sex, ER-age-sex, and ER-VDR-sex. The gene-age-sex interaction has been observed in our previous study (Deng et al. 2002b) by performing a complex segregation analysis in proband ascertained pedigrees from Caucasians. Although the exact mechanism underlying the sexand age-genotype interactions remains to be elucidated, one possible explanation may be lower expression of genes at certain ages and/or differences in gene action in the different genders (Karasik et al. 2000; Deng et al. 2002b; Livshits et al. 2002). Interstudy differences in gender, age, ethnicity, sample size, population structure, and employed statistical methods may also be the reasons for the inconsistent results on the gene-nongenetic factor interaction effects on BMD variation.

When the interactions are significant but not incorporated in the analyses, the main effects of the genotypes may be clouded and thus not detected. This is demonstrated for the association between ER- $\alpha$ and BMD variations at the femoral neck and the trochanter (see Results). Therefore, several significant interaction factors were incorporated into the analyses and thus are expected to yield more convincing results. Further 
studies in other homogeneous populations with larger sample sizes are needed to confirm the results found here.

Acknowledgements This study was supported partially by the $\mathrm{Hu}-$ nan Province Special Professor Start-up Fund (25000612), Chinese National Science Foundation (CNSF) Outstanding Young Scientist Award (30025025), CNSF Grant (30170504) and a key project fund from the Ministry of Education of P. R. China (25000106). Some investigators were partially supported by grants from the National Health Institute (K01 AR02170-01, R01 GM6040201A1) and the US Department of Energy (DE-FG03-00ER63000/ A00). We thank all of the study subjects for volunteering to participate in the study. We thank Ms. Yuejuan Qin and Ms. Qi Zhou for the subject recruitment and BMD measurements and Ms. Qiren Huang for coordinating sample recruitment.

\section{References}

Brown MA, Haughton MA, Grant SF, Gunnell AS, Henderson NK, Eisman JA (2001) Genetic control of bone density and turnover: role of the collagen lalpha1, estrogen receptor, and vitamin D receptor genes. J Bone Miner Res 16:758-764

Deng HW, Li J, Li JL, Johnson M, Gong G, Davis KM, Recker RR (1998) Change of bone mass in postmenopausal Caucasian women with and without hormone replacement therapy is associated with vitamin $\mathrm{D}$ receptor and estrogen receptor genotypes. Hum Genet 103:576-585

Deng HW, Shen H, Xu FH, Deng HY, Conway T, Zhang HT, Recker RR (2002a) Tests of linkage and/or association of genes for vitamin D receptor, osteocalcin, and parathyroid hormone with bone mineral density. J Bone Miner Res17:678-686

Deng HW, Livshits G, Yakovenko K, Xu FH, Conway T, Davies KM, Deng H, Recker RR (2002b) Evidence for a major gene for bone mineral density/content in human pedigrees identified via probands with extreme bone mineral density. Ann Hum Genet 66:61-74

Dennison EM, Arden NK, Keen RW, Syddall H, Day IN, Spector TD, Cooper C (2001) Birthweight, vitamin D receptor genotype and the programming of osteoporosis. Paediater Perinat Epidemiol 15:211-219

Drummond FJ, Wynne F, Mollov MG, Quane KA (2002) Osteoprotegrin, COLIA1 and VDR gene polymorphisms and the rate of bone loss in postmenopausal Irish women. J Bone Miner Res 17:S220 (Abstract)

Efstathiadou Z, Kranas V, Ioannidis JP, Georgiou I, Tsatsoulis A (2001) The Sp1 COLIA1 gene polymorphism, and not vitamin D receptor or estrogen receptor gene polymorphisms, determines bone mineral density in postmenopausal Greek women. Osteoporos Int 12:326-331

Ferrari SL, Rizzoli R, Slosman DO, Bonjour JP (1998) Do dietary calcium and age explain the controversy surrounding the relationship between bone mineral density and vitamin D receptor gene polymorphisms? J Bone Miner Res 13:363-370

Finkelstein JS, Lee ML, Sowers M, Ettinger B, Neer RM, Kelsey JL, Cauley JA, Huang MH, Greendale GA (2002) Ethnic variation in bone density in premenopausal and early perimenopausal women: effects of anthropometric and lifestyle factors. J Clin Endocrinol Metab 87:3057-3067

Gennari L, Becherini L, Masi L, Mansani R, Gonnelli S, Cepollaro C, Martini S, Montagnani A, Lentini G, Becorpi AM, Brandi ML (1998) Vitamin D and estrogen receptor allelic variants in Italian postmenopausal women: evidence of multiple gene contribution to bone mineral density. J Clin Endocrinol Metab 83:939-944

Giguere Y, Dodin S, Blanchet C, Morgan K, Rousseau F (2000) The association between heel ultrasound and hormone replacement therapy is modulated by a two-locus vitamin D and estrogen receptor genotype J Bone Miner Res 15:1076-1084
Graafmans WC, Lips P, Ooms ME, van Leeuwen JP, Pols HA, Uitterlinden AG (1997) The effect of vitamin D supplementation on the bone mineral density of the femoral neck is associated with vitamin D receptor genotype. J Bone Miner Res 12:1241-1245

Ho AY, Yeung SS, Kung AW (2000) PvuII polymorphisms of the estrogen receptor alpha and bone mineral density in healthy southern Chinese women. Calcif Tissue Int 66:405-408

Kanis JA, Melton LJ 3rd, Christiansen C, Johnston CC, Khaltaev N (1994) The diagnosis of osteoporosis. J Bone Miner Res 9:1137-1141

Karasik D, Ginsburg E, Livshits G, Pavlovsky O, Kobyliansky E (2000) Evidence of major gene control of cortical bone loss in humans. Gen Epidem 19:410-421

Kim JG, Lim KS, Kim EK, Choi YM, Lee JY (2001) Association of vitamin D receptor and estrogen receptor gene polymorphisms with bone mass in postmenopausal Korean women. Menopause 8:222-228

Lau EM, Young RP, Lam V, Li M, Woo J (2001) Estrogen receptor gene polymorphism and bone mineral density in postmenopausal Chinese women. Bone 29:96-98

Lau EM, Lam V, Li M, Ho K, Woo J. (2002) Vitamin D receptor start codon polymorphism (Fok I) and bone mineral density in Chinese men and women. Osteoporos Int 13:218-221

Lei SF, Deng FY, Liu XH, Huang QR, Qin Y, Zhou Q, Jiang DK, Li YM, Mo XY, Liu MY, Chen XD, Wu XS, Shen H, Dvornyk V, Zhao L, Recker RR, Deng HW (2003) Polymorphisms of four bone mineral density (BMD) candidate genes in Chinese populations and the comparison with the other populations of different ethnicity. J Bone Miner Metab 21:34-42

Liel Y, Kraus S, Levy J, Shany S (1992) Evidence that estrogen modulated activity increases the number of 1,25-dihydroxyvitamin D receptors in osteoblast-like cells. Endocrinology 130:2597-2601

Liu YZ, Liu YJ, Recker RR Deng HW (2003) Molecular studies of gene identification for osteoporosis: the 2002 update. J Endocrinol 177:147-196

Livshits G, Karasik D, Kobyliansky E (2002) Complex segregation analysis of the radiographic phalanges bone mineral density and their age-related changes. J Bone Miner Res 17:152-161

O'Connell JR, Weeks DE (1998) PedCheck: a program for identification of genotype incompatibilities in linkage analysis. Am J Hum Genet 63:259-266

Qin YJ, Shen H, Huang QR, Zhao LJ, Zhou Q, Li MX, He JW, Lu JH, Deng HW (2003) Estrogen receptor $\alpha$ gene polymorphisms and peak bone mass (PBM) in Chinese nuclear families. J Bone Miner Res 18:1028-1035

Ralston SH (2002) Genetic control of susceptibility to osteoporosis J Clin Endocrinol Metab 87:2460-2466

Rapuri PB, Gallagher JC, Kinyamu HK, Ryschon KL (2001) Caffeine intake increases the rate of bone loss in elderly women and interacts with viamin D receptor genotypes. Am J Clin Nutr 74:694-700

Recker RR, Deng HW (2002) Role of genetics in osteoporosis. Endocrine 17:55-66

Riggs BL, Nguyen TV, Melton LJ 3rd, Morrison NA, O'Fallon WM, Kelly PJ, Egan KS, Sambrook PN, Muhs JM, Eisman JA (1995) The contribution of vitamin D receptor gene alleles to the determination of bone mineral density in normal and osteoporotic women. J Bone Miner Res 10:991-996

Salmen T, Heikkinen AM, Mahonen A, Kroger H, Komulainen M, Saarikoski S, Honkanen R, Maenpaa PH (2000) Early postmenopausal bone loss is associated with PvuII estrogen receptor gene polymorphism in Finnish women: effect of hormone replacement therapy. J Bone Miner Res 15:315-321

Schaid DJ, Jacobsen SJ (1999) Biased tests of association: comparisons of allele frequencies when departing from HardyWeinberg proportions. Am J Epidemiol 149:706-711

Sobel E, Lange K (1996) Descent graphs in pedigree analysis: applications to haplotyping, location scores, and marker-sharing statistics. Am J Hum Genet 58:1323-1337 
Tofteng CL, Jensen JE, Abrahamsen B, Odum L, Brot C (2002) Two polymorphisms in the Vitamin D receptor gene-association with bone mass and 5-year change in bone mass with or without hormone-replacement therapy in postmenopausal women: the Danish osteoporosis prevention study. J Bone Miner Res 17:1535-1544

Willing M, Sowers M, Aron D, Clark MK, Burns T, Bunten C, Crutchfield M, D'Agostino D, Jannausch M (1998) Bone mineral density and its change in white women: estrogen and vitamin $\mathrm{D}$ receptor genotypes and their interaction. $\mathrm{J}$ Bone Miner Res 13:695-705
Yamada Y, Ando F, Niino N, Ohta S, Shimokata H (2002) Association of polymorphisms of the estrogen receptor alpha gene with bone mineral density of the femoral neck in elderly Japanese women. J Mol Med 80:452-460

Zhao J, Zhou X, Meng X, Liu G, Xing X, Liu H, Xu L (1997) Polymorphisms of vitamin $\mathrm{D}$ receptor gene and its association with bone mineral density and osteocalcin in Chinese. Chin Med J 110:366-371 